\title{
Chronic intermittent ethanol exposure selectively increases synaptic excitability in the ventral domain of the rat hippocampus
}

\author{
Sarah E. Ewin ${ }^{1}$, James W. Morgan ${ }^{1}$, Farr Niere ${ }^{1}$, Nate P. McMullen ${ }^{1}$, Samuel H. Barth ${ }^{1}$, \\ Antoine G. Almonte ${ }^{1}$, Kimberly F. Raab-Graham ${ }^{1}$, Jeffrey L. Weiner ${ }^{1, \#}$ \\ ${ }^{1}$ Department of Physiology and Pharmacology Wake Forest School of Medicine Winston-Salem, \\ NC 27157
}

\section{Abstract}

Many studies have implicated hippocampal dysregulation in the pathophysiology of alcohol use disorder (AUD). However, over the past twenty years, a growing body of evidence has revealed distinct functional roles of the dorsal ( $\mathrm{dHC}$ ) and ventral (vHC) hippocampal subregions, with the $\mathrm{dHC}$ being primarily involved in spatial learning and memory and the $\mathrm{vHC}$ regulating anxiety-and depressive-like behaviors. Notably, to our knowledge, no rodent studies have examined the effects of chronic ethanol exposure on synaptic transmission along the dorsal/ventral axis. To that end, we examined the effects of the chronic intermittent ethanol vapor exposure (CIE) model of AUD on $\mathrm{dHC}$ and vHC synaptic excitability. Adult male Long Evans rats were exposed to CIE or air for 10 days (12 hrs/day; targeting blood ethanol levels of 175-225 $\mathrm{mg} \%$ ) and recordings were made 24 hours into withdrawal. As expected, this protocol increased anxiety-like behaviors on the elevated plus-maze and successive alleys test. Extracellular recordings revealed marked CIE-associated increases in synaptic excitation in the CA1 region that were exclusively restricted to the ventral domain of the hippocampus. Western blot analysis of synaptoneurosomal fractions revealed that the expression of two proteins that regulate synaptic strength, GluA2 and SK2, were dysregulated in the $\mathrm{vHC}$, but not the $\mathrm{dHC}$, following CIE. Together, these findings suggest that the ventral CA1 region may be particularly sensitive to the maladaptive effects of chronic ethanol exposure and provide new insight into some of the neural substrates that may contribute to the negative affective state that develops during withdrawal.

\section{Keywords}

Chronic intermittent ethanol; Anxiety; ventral hippocampus; dorsal hippocampus; SK calciumactivated potassium channels; withdrawal

\footnotetext{
\#Corresponding author: Jeffrey L. Weiner, Ph.D., Department of Physiology \& Pharmacology, Wake Forest School of Medicine, Winston-Salem, NC 27157 USA, Tel: (336) 716-8692 Fax: (336) 716-8501, jweiner@ wakehealth.edu.

Publisher's Disclaimer: This is a PDF file of an unedited manuscript that has been accepted for publication. As a service to our customers we are providing this early version of the manuscript. The manuscript will undergo copyediting, typesetting, and review of the resulting proof before it is published in its final citable form. Please note that during the production process errors may be discovered which could affect the content, and all legal disclaimers that apply to the journal pertain.
} 


\section{Introduction}

Alcohol use disorder (AUD) affects over 16.3 million Americans and is a worldwide socioeconomic and public health problem, accounting for more than $6 \%$ of the global burden of disease (Center for Behavioral Health Statistics, 2015; World Health Organization, 2003). AUD is a chronic relapsing disorder that is characterized by a transition from recreational drinking to excessive alcohol use, involving a shift from positive reinforcement to negative reinforcement (Koob, 2015; Koob and Volkow, 2016) . In other words, individuals are initially motivated to drink primarily because of the pleasurable effects of alcohol consumption but eventually become drawn to alcohol to avoid the negative affective feelings that emerge during periods of abstinence.

Many studies have shown that anxiety represents an important element of the negative affective state that develops during withdrawal from chronic alcohol exposure (Becker, 2008; Breese et al., 2011). In fact, individuals with anxiety and stressor-related disorders are 2-4 times more likely to develop AUD, are diagnosed with AUD significantly earlier than individuals without comorbid anxiety disorders, and this dual diagnosis is associated with much poorer treatment outcomes (Kushner et al., 2005, 2011; Smith and Randall, 2012). Withdrawal-associated anxiety is also a major contributing factor to relapse in treatmentseeking individuals (Sinha et al., 2011). Additionally, stress and alcohol-associated cues trigger robust increases in craving in abstinent alcoholics that are associated with increased anxiety and negative affect. Additionally, the magnitude or intensity of this craving is a strong predictor of relapse (Sinha et al., 2009).

Despite the clinical importance of understanding the neural substrates responsible for the negative affective state that develops following chronic alcohol exposure and withdrawal, much remains unknown regarding the specific brain regions and circuits that mediate withdrawal-associated increases in anxiety behaviors and alcohol drinking. One preclinical model of AUD that has been extensively validated to address these questions is the chronic intermittent ethanol (CIE) vapor exposure regimen (Becker, 2017; Gilpin et al., 2008; Reynolds and Berridge, 2008; Vendruscolo and Roberts, 2014). Using this model, which involves daily cycles of ethanol vapor exposure followed by a withdrawal period, rats and mice develop physiological and behavioral signs of ethanol dependence, including marked escalations in ethanol self-administration (Criado and Ehlers, 2013; Finn et al., 2007; O'Dell et al., 2004) and increases in anxiety-like behaviors on assays like the elevated plus-maze (Cagetti et al., 2004).

Elegant neurobiological studies have used the CIE procedure to identify key elements of the neural circuitry that drives the maladaptive withdrawal-associated behaviors promoted by this model. Most recent studies have focused on the prefrontal cortex, amygdala nuclei, and the bed nucleus of the stria terminalis, regions that comprise interconnected circuits known to play an integral role in negative affective states. These studies have shown that withdrawal from CIE increases synaptic excitability within these circuits and that these maladaptive changes drive negative affective behaviors (Christian et al., 2012b; Conrad and Winder, 2011; de Guglielmo et al., 2016; Den Hartog et al., 2016; Diaz et al., 2011; Holmes et al., 2012; Lack et al., 2007; Marcinkiewcz et al., 2016; Pleil et al., 2015). 
The hippocampus is another brain region that is intimately connected to the circuitry that governs negative emotional states. This structure runs along a ventral-dorsal axis in rodents, which corresponds to an anterior-posterior axis in humans (Strange et al., 2014). While the intrinsic circuitry of the dorsal and ventral domains is similar, these subregions are comprised of distinct afferent and efferent projections (Strange et al., 2014). Notably, the ventral domain of the hippocampus makes strong monosynaptic, reciprocal connections to several nodes of the emotional network and has long been known to play an integral role in anxiety-like behaviors (Bannerman et al., 2003; Fanselow and Dong, 2010; Felix-Ortiz et al., 2013; Huff et al., 2015; Kjelstrup et al., 2002; Maggio and Segal, 2007, 2009; Strange et al., 2014). In support of this, recent optogenetic studies have demonstrated that the excitatory projection from the basolateral amygdala (BLA) to the ventral hippocampus (vHC) can bidirectionally modulate anxiety-like behaviors in a manner similar to that observed via manipulations of the canonical basolateral-central amygdala "anxiety" circuit (Felix-Ortiz et al., 2013; Felix-Ortiz and Tye, 2014). Moreover, optical inhibition of the BLA-vHC circuit also disrupts the consolidation of footshock-associated fear, but not contextual, fear learning (Huff et al., 2015). In contrast, the dHC contains the greatest density of place cells that encode spatial location and these cells send strong excitatory projections to areas like the dorsal subiculum, retrosplenial cortex and anterior cingulate cortex, regions known to play an integral role in cognitive processing of visual information (Fanselow and Dong, 2010; Jung et al., 1994; Kjelstrup et al., 2002; Potvin et al., 2007; Tannenholz et al., 2014).

Although several studies have reported that CIE promotes increases in hippocampal excitability (Hendricson et al., 2007; Nelson et al., 2005; Roberto et al., 2001), to our knowledge none have directly compared the effects of CIE on synaptic transmission in the dorsal and ventral domains of the hippocampus. To that end, we employed electrophysiological and biochemical approaches to assess the effects of CIE on synaptic excitability in the rat $\mathrm{dHC}$ and vHC. We hypothesized that withdrawal following CIE would promote increases in synaptic excitability in both subregions of the hippocampus. However, given that negative affective behaviors are some of the most sensitive alterations observed following ethanol withdrawal (Morales et al., 2018; Rose et al., 2016; Sidhu et al., 2018), we also predicted that CIE-associated synaptic alterations would be most robust in the vHC. Here we report that withdrawal following CIE markedly increases measures of synaptic excitability in the ventral domain of the hippocampus while modestly decreasing synaptic excitation in the dorsal subregion. We further identify changes in two synaptic proteins, the AMPA receptor (AMPAR) subunit GluA2 and the small conductance $\mathrm{Ca}^{2+}$-activated $\mathrm{K}^{+}$channel subunit 2 (SK2), that may contribute to these divergent adaptations.

\section{Methods}

\section{Subjects}

Male Long Evans rats were purchased from Envigo, IN and arrived at 175-200g. Upon arrival rats were singly housed in clear cages $(25.4 \mathrm{~cm} \times 45.7 \mathrm{~cm})$ and maintained on a reverse 12 hour: 12 hour light dark cycle with lights on at 9pm. Rats had ad libitum access to food (Prolab RMH 3000, LabDiet: PMI Nutrition International, St. Louis, MO) and water throughout the study. Animal care procedures were carried out in accordance with the NIH 
Guide for the Care and Use of Laboratory Animals and were approved by the Wake Forest University Animal Care and Use Committee. A total of 12 CIE and 12 AIR rats were used for the elevated plus-maze and open field tests. An additional group of rats was run for the Alley Test (AIR $=19$ rats; $\mathrm{CIE}=18$ rats). A separate group of rats was used for the electrophysiological studies (AIR $=10$ rats; $\mathrm{CIE}=9$ rats) with 3-4rats from each AIR and CIE cohort used for tissue for the Western Blots (1 rat in each group was an outlier in the SK2 and GluA2 Western blots and there data were not used in the analyses).

\section{Chronic intermittent ethanol vapor inhalation exposure}

Animals in the CIE condition were housed in their standard home cages which were placed in custom-built Plexiglas chambers (Triad Plastics, Winston-Salem, NC). Ethanol vapor was pumped into the chamber for 12 hours a day for 10 consecutive days during the light cycle (9pm to 9am). Control animals (AIR) were housed in the same manner with their home cages placed inside the custom-built Plexiglas chambers on the same light cycle, but were exposed only to room air. Animals were weighed daily and tail blood samples were taken every other day during the 10 day CIE procedure at 9am to monitor blood ethanol concentrations (BECs). Following the 10 days of CIE, animals underwent 24 hours of withdrawal (no ethanol vapor) and were then run on behavioral assays or sacrificed for electrophysiological or biochemical studies. Blood Ethanol Determination

Blood ethanol concentrations (BECs) were measured on the first, fifth, and tenth day of CIE exposure at $9 \mathrm{am}$. In some cases an additional BEC was measured in addition to those three. $10 \mu \mathrm{L}$ of blood was collected from a tail snip of each rat. BECs were determined using a commercially available alcohol dehydrogenase enzymatic assay kit (Carolina Liquid Chemistries Corporation, Brea, CA). Ethanol concentrations were then determined using a spectrophotometer (Molecular Devices Spectra Max). The target range for BECs was 175 $225 \mathrm{mg} / \mathrm{dL}$, with the average BEC of all animals included being $213.79 \pm 6.39$.

\section{Elevated Plus-Maze}

Anxiety-like behavior was assessed in a subset of the CIE and AIR ( $n=12$ in each condition) animals following 24 hours of withdrawal using standard elevated plus-mazes (Med Associates, St. Albans, VT) raised $72.4 \mathrm{~cm}$ from floor level, with runways measuring 10.2 $\mathrm{cm}$ wide by $50.8 \mathrm{~cm}$ long. Open runways had $1.3 \mathrm{~cm}$ high lips and closed runways were enclosed in $40.6 \mathrm{~cm}$ high black polypropylene walls. Exits and entries from runways were detected via infrared sensors attached to the opening of each arm of the maze. Data were obtained and recorded via personal computer interfaced with control units and MED-PC programming (Med Associates). Animals were placed at the junction of the four arms at the beginning of the session, and activity was measured for five minutes. Anxiety-like behavior was assessed by measuring the total time spent on the open arms of the maze as well as the number of entries into the open arms. General locomotor activity was assessed by measuring the number of closed arm entries.

\section{Open Field Test}

Immediately following the elevated plus maze, general locomotion in a novel environment was measured using an open field test conducted in Plexiglass chambers $(41.5 \mathrm{~cm} \times 41.5 \mathrm{~cm}$ 
$\mathrm{x} 30 \mathrm{~cm}$ ). At the start of the test, animals were placed in the center of the chambers equipped with Omnitech Superflex Sensors (Omnitech Electronics, Inc.), which utilize arrays of infrared photodetectors located at regular intervals along each way of the chambers. The chamber walls were solid and contained within sound attenuating boxes with 15 watt light bulbs to illuminate the arena. Exploratory activity in this environment was measured for 30 minutes, and data were analyzed in five minute time bins.

\section{Successive alleys test}

In a separate set of CIE and AIR exposed rats, the successive alleys test was run to obtain another assessment of anxiety-like behavior. The successive alley test consists of a linear series of four alleys designed to be increasingly anxiogenic. The first alley (or zone) is enclosed, while the three successive alleys (or zones) resemble the open arms of the plusmaze but each becomes narrower, has lower side wall height, and a brighter floor color (Deacon, 2013; Lahmann et al., 2014; Rudebeck et al., 2007). The test is raised $61 \mathrm{~cm}$ from the floor level with $36.1 \mathrm{~cm}$ walls in zone 1 and $3.81 \mathrm{~cm}$ walls in zones 2-4 with a total alley length of $172.72 \mathrm{~cm}$. Each zone is $43.18 \mathrm{~cm}$ in length. Zones 1 and 2 are $15.24 \mathrm{~cm}$ wide while zone 3 is $10.16 \mathrm{~cm}$ and zone 4 is $5.08 \mathrm{~cm}$ wide. EthoVision (Noldus) was used to analyze the total distance traveled, velocity, time spent in each zone, and head dips in each zone. The assay lasted for a total of 5 minutes.

\section{Electrophysiology}

After the induction of a deep anesthetic plane with isoflurane, rats were decapitated, and their brains removed and placed in ice-cold cutting artificial cerebral spinal fluid (aCSF) consisting of $85 \mathrm{mM} \mathrm{NaCl}, 1.25 \mathrm{mM} \mathrm{NaH}_{2} \mathrm{PO}_{4}, 25 \mathrm{mM} \mathrm{NaHCO}_{3}, 10 \mathrm{mM}$ D-Glucose, 75 $\mathrm{mM}$ sucrose, $3 \mathrm{mM} \mathrm{KCl}, 7 \mathrm{mM} \mathrm{MgCl}_{2}, 0.5 \mathrm{mM} \mathrm{CaCl}_{2}$, and $0.6 \mathrm{mM}$ ascorbate bubbled with $95 \% \mathrm{O}_{2}$ and $5 \% \mathrm{CO}_{2}$. Transverse slices containing the $\mathrm{dHC}$ and vHC were cut at a thickness of $375 \mu \mathrm{m}$ using a VT1000S Vibratome (Leica Microsystems)., Differentiation of ventral and dorsal slices was noted prior to recording using definitions from Maruki et al (2001) and Fanselow and Dong (2010). Incubation of slices occurred for at least one hour at room temperature $\left(21-23^{\circ} \mathrm{C}\right)$ in aCSF consisting of $125 \mathrm{mM} \mathrm{NaCl}, 1.25 \mathrm{mM} \mathrm{NaH}_{2} \mathrm{PO}_{4}, 25 \mathrm{mM}$ $\mathrm{NaHCO}_{3}, 10 \mathrm{mM}$ D-Glucose, $2.5 \mathrm{mM} \mathrm{KCl}, 1 \mathrm{mM} \mathrm{MgCl}$, and $2 \mathrm{mM} \mathrm{CaCl}_{2}$ bubbled with $95 \% \mathrm{O}_{2}$ and $5 \% \mathrm{CO}_{2}$ before experiments commence. Slices were transferred to a recording chamber and perfused with oxygenated, heated (to $32{ }^{\circ} \mathrm{C}$ ) $0.86 \mu \mathrm{m}$ ) were pulled using a horizontal pipette puller (P-97; Sutter Instrument) to prepare recording electrodes (1-3 M $\Omega$ resistance). To acquire extracellular field potentials the glass capillary tubes were filled with $0.9 \%$ saline. Extracellular field recordings were obtained from Schaffer collateral $\rightarrow$ CA1 synapses of the $\mathrm{dHC}$ or vHC using nickel dichromate bipolar stimulating electrodes. For input-output curves, field excitatory post synaptic potentials (fEPSP) were evoked every 10 seconds at 10,20,50,100,150,200,300,500, and $700 \mu \mathrm{A}$ five times per stimulus intensity. All recordings were acquired using an Axoclamp 2B amplifier, digitized (Digidata 1321A; Molecular Devices) and analyzed with pClamp 10.4 software (Molecular Devices).

\section{Western blotting}

Western blot analyses were performed on synaptoneurosomes (SNs) that were obtained from hippocampal slices that were prepared similarly for electrophysiology experiments. (See 
Electrophysiology methods above). Briefly, whole $\mathrm{dHC}$ and vHC slices were homogenized in buffer (50 mM Tris, $\mathrm{pH}$ 7.35; protease and phosphatase inhbitors (Halt, ThermoFisher)). Homogenates were sequentially filtered through $100 \mu \mathrm{m}$ and $5 \mu \mathrm{m}$ filters to produce SNs (Niere et al., 2016; Quinlan et al., 1999; Workman et al., 2013). SNs were centrifuged $\left(14,000 \mathrm{~g}, 20 \mathrm{~min}, 4^{\circ} \mathrm{C}\right)$ to obtain a pellet that was solubilized in RIPA buffer $(150 \mathrm{mM} \mathrm{NaCl}$; $10 \mathrm{mM}$ Tris, $\mathrm{pH}$ 7.4; $0.1 \%$ SDS; $1 \%$ Triton X-100; $1 \%$ deoxychoate 5 mM EDTA; Halt). The insoluble fraction of SNs was removed by centrifugation at $14,000 \mathrm{~g}, 20 \mathrm{~min}, 4^{\circ} \mathrm{C}$. The soluble fraction was used for immunoblot analysis. $50 \mu \mathrm{g}$ of protein were run for each sample and separated by SDS-PAGE. The following antibodies were used to visualize the proteins of interest: mouse anti-GluA2 (1:2000; Neuromab; Davis, CA); rabbit anti-SK2 (1:1000; Alomone Lab, Jerusalem, Israel); rabbit anti-GluN1 (1:1000; Alomone Lab, Jerusalem, Israel); rabbit anti-GluN2B (1:500; Alomone Lab, Jerusalem, Israel); mouse antiactin (1:10,000; Sigma; St. Louis, MO). To visualize the proteins, membranes were incubated in fluorescence-conjugated secondary antibodies (AF680; AF800; 1:4000; LiCor, Lincoln, NE) and imaged using the Odyssey CLx infrared imaging system. For densitometry analysis of proteins, ImageJ software (National Institutes of Health) was used.

\section{Data Analysis and Statistics}

Elevated plus-maze and Western blot data were analyzed using unpaired t-tests, or MannWhitney Rank Sum Tests in the event of non-normally distributed data. One tailed t-tests were used to analyze the Western blot data because, based on our electrophysiological findings, we had a priori hypotheses regarding the direction of expected changes in SK2 and GluA2 expression following CIE. Successive alleys test data were analyzed using two way ANOVAs. Open field test data and electrophysiology data were analyzed using two way repeated measures ANOVAs. Where noted, post hoc analysis was conducted using Bonferroni's multiple comparison test. A generalized linear model was run in SAS to examine the relationship between CIE, fiber volley amplitude and fEPSP slope using ANCOVAs. The minimal level of significance was set as $p<0.05$ for all analyses.

\section{Results}

\section{Chronic intermittent ethanol exposure increases anxiety-like behaviors}

Anxiety-like behavior was assessed $24 \mathrm{hr}$ following the CIE exposure paradigm using the elevated plus-maze, open field exploration, and the successive alleys test. On the elevated plus-maze, CIE animals $(n=12)$ exhibited an increases in anxiety-like behavior, as evidenced by less time spent on the open arms (Figure 1A; $\mathrm{t}(22)=198.5 ; \mathrm{p}=0.005$; twotailed) and less open arm entries (Figure 1B; $\mathrm{t}(22)=198.0 ; \mathrm{p}=0.005$; two-tailed). CIE and AIR $(\mathrm{n}=12)$ animals also showed a significant difference in closed arm entries (Figure 1C; $\mathrm{t}(22)=4.168 ; \mathrm{p}<0.001)$, typically used as a measure of non-specific locomotion. In the open field assay, CIE animals did not differ from AIR animals in overall locomotor activity (Figure 1D), as evidenced by no significant main effect of condition (AIR or CIE) $\left(\mathrm{F}_{1,110}=\right.$ $0.128 ; \mathrm{p}=0.72)$. There was a significant main effect of time $\left(\mathrm{F}_{1,110}=61.155 ; \mathrm{p}<0.001\right)$, as rodents acclimated to the novel arena, but no significant interaction between condition and time $\left(\mathrm{F}_{1,110}=0.445 ; \mathrm{p}=0.82\right)$. Additionally, the time spent in the center of the arena was not different across groups (data not shown; no main effect of condition $\left(F_{1,110}=0.341 ; \mathrm{p}=\right.$ 
$0.565)$ or time $\left(\mathrm{F}_{1,110}=1.469 ; \mathrm{p}=0.206\right)$; no interaction between condition and time $\left(\mathrm{F}_{1,110}=0.477 ; \mathrm{p}=0.793\right)$.

To further characterize the effect of CIE on anxiety-like behaviors, we constructed a modified successive alleys test (Deacon, 2013) and tested a separate cohort of AIR ( $\mathrm{n}=19)$ and CIE $(n=18)$ rats on this assay. This test consists of a linear series of four alleys designed to be increasingly anxiogenic. The first alley or zone is similar to an enclosed arm of an elevated plus-maze, and the three successive alleys resemble the open arm of the plusmaze but become progressively narrower, have lower side wall height, and a brighter floor color. A two-way ANOVA revealed a significant difference in time spent in the four zones $\left(\mathrm{F}_{3,140}=115.261, \mathrm{p}<0.001\right)$, no effect of CIE $\left(\mathrm{F}_{1,140}=0.996\right)$ but a trend of an interaction between these factors (Figure 2A; $\mathrm{F}_{3,140}=2.331, \mathrm{p}<0.08$ ). Planned post-hoc comparisons confirmed that both control and CIE subjects spent the most time in the enclosed arm and significantly less time in each of the next two open zones. Neither cohort exhibited a difference in time spent between the last two zones. Although there was no overall effect of treatment, possibly due to a floor effect resulting from the relatively anxiogenic conditions of our first experiments with this assay, CIE rats did spend significantly more time in the enclosed arm that air-exposed subjects $\left(\mathrm{q}_{1,35}=3.111, \mathrm{p}<0.03\right)$. A similar analysis of head dips, often used as a measure of anxiety-like behavior on the plus-maze, revealed a significant effect of zone $\left(\mathrm{F}_{1,140}=27.816, \mathrm{p}<0.001\right)$ and CIE $\left(\mathrm{F}_{1,140}=8.237, \mathrm{p}<0.01\right)$ but no interaction between these factors (F3,140 $=1.263$ ) (Figure 2B; Bailey and Crawley, 2009; Rodger et al., 1997). Post-hoc comparisons indicated that both treatment groups exhibited significantly more head dips in the first open zone, relative to the other two zones, consistent with the idea that this zone was relatively less anxiogenic than the two narrow open alleys. This analysis also revealed that CIE rats made significantly fewer head dips in the first open zone $\left(\mathrm{q}_{1,35}=4.057, \mathrm{p}<0.01\right)$. Importantly CIE had no effect on total distance travelled or velocity on this assay (Figure 2C and 2D).

\section{Chronic intermittent ethanol exposure produces divergent effects on hippocampal excitability}

To determine whether CIE altered hippocampal excitability, extracellular field excitatory postsynaptic potentials (fEPSPs) were recorded in the hippocampal Schaffer-collateral-CA1 region (Almonte et al., 2017). All recordings were conducted at 24-32 hours into withdrawal, a time range similar to that associated with the CIE-associated increases in anxiety-like behaviors that we observed. We recorded afferent fiber volley amplitudes and the rising slope of fEPSPs in response to increasing stimulus intensity levels to generate input-output curves. In the vHC (Figure 3A), there was no main effect of treatment condition on fiber volley amplitude (Figure $4 \mathrm{~A} ; \mathrm{F}_{1,95}=0.963 ; \mathrm{p}=0.35$ ), but there was a main effect of stimulation intensity ( $\left.F_{1,95}=50.796 ; p<0.001\right)$ (AIR $n=6$ slices, 5 rats; CIE $n=8$ slices, 7 rats). Although there was no significant interaction between treatment condition and stimulation intensity $\left(\mathrm{F}_{1,95}=1.472 ; \mathrm{p}=0.13\right)$, given our a prioiri hypothesis that CIE would promote increases in synaptic excitability, we conducted additional post-hoc analyses which revealed a significant facilitatory effect of CIE on fiber volley amplitude, albeit only at the highest stimulus intensity tested (Figure 4A; $p=0.01$ ). In regards to the fEPSP slope (Figure 4B), there was a main effect of treatment condition $\left(\mathrm{F}_{1,95}=7.231 ; \mathrm{p}=0.02\right)$, as well as 
stimulation intensity $\left(\mathrm{F}_{1,95}=46.302 ; \mathrm{p}<0.001\right)$. In addition, there was a significant interaction between condition and stimulation intensity on fEPSP slope $\left(F_{1,95}=46.302 ; \mathrm{p}\right.$ $<0.001)$. We then used a model to conduct an analysis of covariance to further understand how withdrawal from CIE altered the relationship between afferent volley amplitude and fEPSP slope. This analysis revealed a significant effect of fiber volley amplitude (Figure 4C; $\left.\mathrm{F}_{1,124}=108.26 ; \mathrm{p}<0.0001\right)$, but not treatment condition $\left(\mathrm{F}_{1,124}=0.01 ; \mathrm{p}=0.94\right)$, on fEPSP slope. There was also a significant interaction between fiber volley amplitude and CIE on fEPSP slope $\left(F_{1,124}=47.01 ; p<0.0001\right)$. This analysis yielded a parameter estimate of 1.039 , which indicates that, in the vHC of CIE animals, the fiber volley's positive effect on fEPSP slope is greatly increased, resulting in an overall enhancement of excitability.

In the $\mathrm{dHC}$ (Fig 3B), there was no main effect of treatment condition on afferent volley amplitude (Figure 5A; $\mathrm{F}_{1,133}=2.112 ; \mathrm{p}=0.216$ ) but there was a main effect of stimulation intensity on this parameter $\left(\mathrm{F}_{1,133}=63.662 ; \mathrm{p}<0.001\right)$ (AIR $\mathrm{n}=10$ slices, 9 rats; CIE $\mathrm{n}=9$ slices, 8 rats). Although there was no significant interaction between treatment condition and stimulation intensity in the $\mathrm{dHC}\left(\mathrm{F}_{1,133}=1.106 ; \mathrm{p}=0.44\right)$, post hoc analyses revealed a significant increase in afferent volley amplitude in CIE slices at the two highest stimulation intensities, 500 and $700 \mu \mathrm{A}$ ( $\mathrm{p}=0.05$ at both intensities). Additionally, there was no main effect of treatment condition on fEPSP slope (Figure 5B; $F_{1,133}=0.862 ; p=0.78$ ), but there was a main effect of stimulation intensity on fEPSP slope $\left(\mathrm{F}_{1,8}=49.184 ; \mathrm{p}<0.001\right)$. There was no interaction between treatment condition and stimulation intensity in the $\mathrm{dHC}\left(\mathrm{F}_{1,8}=\right.$ $0.405 ; p=0.92$ ) and post hoc analyses confirmed no effect of CIE on fEPSP slope at any of the stimulation intensities tested. When we used a model to conduct an analysis of covariance of all of the dHC data, there was a significant effect of fiber volley amplitude $\left(\mathrm{F}_{1,166}=304.04 ; \mathrm{p}<0.0001\right)$, but not CIE, on fEPSP slope (Figure 5C; $\mathrm{F}_{1,166}=1.13 ; \mathrm{p}=$ 0.29 ), and the interaction between fiber volley amplitude and CIE on fEPSP slope was also significant $\left(\mathrm{F}_{1,166}=15.35 ; \mathrm{p}<0.0001\right)$. This analysis yielded a parameter estimate of -0.567 , which indicates that in the $\mathrm{dHC}$ of CIE animals, the fiber volley's positive effect on fEPSP slope is actually decreased, consistent with an overall decrease in excitability.

\section{Chronic intermittent ethanol exposure has divergent effects on GluA2 and SK2 protein expression in the ventral hippocampus, with no effects on GluN1 and GluN2B protein expression in the hippocampus}

In an initial attempt to identify potential mechanisms that may contribute to the marked differences in synaptic adaptation observed in the $\mathrm{vHC}$ and $\mathrm{dHC}$ following CIE, we used Western blots to analyze protein expression differences in synaptoneurosome (SN) fractions prepared from the vHC and dHC. We first focused on the AMPAR GluA2 subunit, whose expression has been linked with CIE-associated increases in synaptic excitability, and the small-conductance $\mathrm{Ca}^{2+}$-activated $\mathrm{K}^{+}$channel subunit SK2, a protein that strongly buffers synaptic transmission, particularly in the vHC, and whose expression has been shown to be reduced by CIE (Adelman et al., 2012; Bond et al., 1999; Hopf et al., 2010a, 2010b; Mulholland et al., 2009, 2011). Additionally, we examined the effects of CIE exposure on the NMDA receptor subunits GluN1 and GluN2B, as both these subunits have also been shown to be altered following CIE (Spencer et al., 2016; Wills et al 2012; Wills et al., 2017). We found that, following CIE, there was a significant increase in GluA2 expression in SNs 
from the vHC, but not dHC, of CIE animals (Figure 6A-D; vHC t $(4)=2.203, \mathrm{p}=0.05$, AIR $=1 \pm 0.0298, \mathrm{n}=3 ; \mathrm{CIE}=1.497 \pm 0.224, \mathrm{n}=3$; one tailed, unpaired students t-test; $\mathrm{dHC} \mathrm{t}(4)$ $=1.144, \mathrm{p}=0.11 \mathrm{AIR}=1 \pm 0.088, \mathrm{CIE} 1.148 \pm 0.053, \mathrm{n}=3$, one tailed unpaired student $\mathrm{t}-$ test). Additionally, we found that SK2 expression was decreased in the vHC of CIE animals (Figure 6A\&E; $\mathrm{t}(4)=3.779, \mathrm{p}=0.01, \mathrm{AIR}=1 \pm 0.019, \mathrm{CIE}=0.721 \pm 0.0713, \mathrm{n}=3$; one tailed, unpaired students t-test), with no changes detected in the dHC (Figure 6B\&F; $t(4)=$ $0.994, \mathrm{p}=0.22, \mathrm{AIR}=1 \pm 0.171, \mathrm{CIE}=1.197 \pm 0.993, \mathrm{n}=3$; one tailed, unpaired students $\mathrm{t}$ test). Finally, we looked at both GluN1 and GluN2B expression in SNs from the vHC and $\mathrm{dHC}$ of CIE animals and found no changes in expression of these NMDA receptor subunits in either hippocampal subregion following CIE exposure (Fig 7B\&D GluN1 dHC $\mathrm{t}(6)=$ $0.314, p=0.76$, AIR $=1 \pm 0.420$, CIE $=0.850 \pm 0.227$; Fig 7B\&F GluN2B dHC $t(6)=1.389$, $\mathrm{p}=0.21, \mathrm{AIR}=1 \pm 0.209, \mathrm{CIE}=0.656 \pm 0.132 ;$ Fig 7A\&C GluN1 vHC t $(6)=0.413, \mathrm{p}=0.69$, $\mathrm{AIR}=1 \pm 0.484$, CIE $=0.899 \pm 0.038$; Fig 7A\&E GluN2B vHC $\mathrm{t}(6)=0.225, \mathrm{p}=0.83$, AIR = $1 \pm 0.220, \mathrm{CIE}=0.926 \pm 0.244 ; \mathrm{CIEN}=4$; AIR $\mathrm{N}=4$ ). Together these findings indicate that, following 10 days of CIE and one day of withdrawal, CIE exposure leads to an increase in SN expression of GluA2 and decreased levels of SK2, exclusively in the ventral region of the rat hippocampus, with no changes in GluN1 or GluN2B in either hippocampal subregion.

\section{Discussion}

The results of this study demonstrate that withdrawal following CIE produces divergent effects on hippocampal excitability in male Long Evans rats. We first replicated previous work showing that the CIE regimen leads to significant increases in anxiety-like behavior (Morales et al., 2015, 2018; Rose et al., 2016). An analysis of the effects of CIE on synaptic excitability within the $\mathrm{CA} 1$ region of the $\mathrm{vHC}$ and $\mathrm{dHC}$ revealed that $\mathrm{CIE}$ promoted robust increases in excitability in the ventral subregion but actually led to a modest but significant decrease in excitation in the $\mathrm{dHC}$. The CIE-associated enhancement of synaptic transmission in the $\mathrm{vHC}$ was accompanied by a significant increase in synaptosomal (SN) GluA2 expression and a decrease in SK2 levels. In marked contrast, levels of these synaptic proteins were not affected by CIE in the $\mathrm{dHC}$, nor were GluN1 and GluN2B expression different in either hippocampal subregion. Collectively, these studies reveal that the observed CIEassociated increases in synaptic excitability in the CA1 of the hippocampus were restricted to the ventral domain of this brain region and identify two synaptic proteins that may contribute to the differential effects of CIE on synaptic excitation in the $\mathrm{vHC}$ and $\mathrm{dHC}$ to CIE.

Withdrawal-induced anxiety symptoms are a hallmark of long term alcohol exposure and play a large role in relapse for individuals with AUD (Driessen, 2001; Schellekens et al., 2015). As reported in many prior studies (Morales et al., 2015, 2018; Zhao et al., 2007), we found that CIE exposure led to a decrease in open arm time and open arm entries on the elevated plus-maze, consistent with an increase in anxiety-like behavior. Although we unexpectedly observed a decrease in closed-arm entries, which may reflect a general decrease in motoric activity, no CIE-associated locomotor effects were observed in the open field assay. 
Because anxiety is a complex, multidimensional behavior that may not be fully captured by any individual test (Ramos and Mormede, 1998), we sought to examine the effects of CIE on the successive alleys test, a relatively novel assay of anxiety-like behavior that, to our knowledge, has not been used to assess the effects of chronic ethanol exposure. This test is a variation on the elevated plus-maze, consisting of a linear series of four alleys, each with increasingly anxiogenic properties. This assay eliminates the elevated plus-maze junction, where the animal's "anxiety" state is ambiguous, and by creating an "anxiety gradient", may offer increased sensitivity over tests like the elevated-plus maze and light/dark box, that offer only a binary choice between two zones (Deacon, 2013; Lahmann, et al, 2014). Despite the relatively anxiogenic conditions under which we conducted our first studies with this assay (relatively little time spent in the most anxiogenic zone across both groups), CIE rats did exhibit significant increases in anxiety-like behavior (spending more time in the enclosed zone and decreased head dips in the first open zone relative to AIR rats) and, importantly, these changes were observed in the absence of any CIE-associated changes in measures of locomotor activity on this assay. Collectively, these findings suggest that the CIE procedure employed in these studies was associated with significant increases in multiple measures of anxiety-like behavior.

Several prior studies have employed electrophysiological approaches to characterize the effects of chronic ethanol exposure on measures of hippocampal synaptic activity. For example, Whittington and Little (1990) found that, after 12 weeks of chronic voluntary ethanol intake and just a few hours of withdrawal (ranging from 3 to 7 hours), hippocampal slices (CA1 area) exhibited decreases in the threshold needed to evoke population spikes, indicating an increase in excitability following chronic ethanol. Additionally, intracellular recordings form CA1 pyramidal cells of the hippocampus of rats 3 weeks into withdrawal from a 20 week chronic ethanol liquid diet, showed a significant reduction in inhibitory postsynaptic currents, as well as reduced post-spike afterhyperpolarization when compared with control rats (Durand and Carlen, 1984). Another study, using CIE vapor exposure similar to that employed in this study ( 2 week of CIE, $24 \mathrm{hr}$ withdrawal), reported increases in synaptic excitability upon increasing stimulation intensities, compared with controls (Roberto et al., 2002). This effect was normalized when they examined hippocampal tissue 5 days into withdrawal. Interestingly, using a similar CIE exposure but with no withdrawal (ethanol continuously washed on the slice) or a very brief withdrawal (slices were prepared for recording 2 hours or less after the CIE exposure concluded), the fEPSP responses in the hippocampus were significantly reduced in CIE rats compared to controls (Nelson et al., 1999).

Notably, none of these prior studies differentiated between the ventral and dorsal regions of the hippocampus in their analyses. A growing body of evidence suggests that these hippocampal subregions have distinct afferent and efferent connectivity and may play differential roles in a range of behavioral and cognitive measures (Fanselow and Dong, 2010; Felix-Ortiz et al., 2013; Risold and Swanson, 1996). Of greatest relevance to this study, the ventral domain of the hippocampus is reciprocally connected to emotional regions, like the basolateral amygdala, and these circuits play an integral role in fear and anxiety-like behaviors (Felix-Ortiz et al., 2013; Huff et al., 2015). To that end, we sought to examine the effects of CIE on synaptic excitability within the CA1 region of the ventral and dorsal 
subdivisions of the hippocampus. Analysis of input-ouput curves revealed a significant increase in the amplitude of the presynaptic fiber volley and a marked enhancement of fEPSP slope in recordings from the CA1 region of CIE slices taken from the vHC. A statistical model that was constructed to assess how CIE influenced the interaction between these two synaptic measures revealed a strong overall CIE-dependent increase in synaptic excitability in the vHC. Surprisingly, this same analysis revealed that CIE was associated with a more modest, but significant, decrease in synaptic excitability in the $\mathrm{dHC}$.

These profound subregional differences are consistent with the notion that the $\mathrm{dHC}$ and vHC subserve distinct functions, with the vHC playing an integral role in emotional measures like anxiety (Fanselow and Dong, 2010; Henke, 1990; Moser et al., 1995; Moser and Moser, 1998; O'Leary and Cryan, 2014). Lesions of the vHC, but not the dHC, result in decreases in anxiety-like behaviors as well as reduced fear expression (Bannerman et al., 2003, 2004; Kjelstrup et al., 2002). Conversely, lesions of the dHC, but not the vHC, result in impaired learning in the Morris water maze, a well validated test of hippocampus-dependent spatial learning (Moser et al., 1995; O'Leary and Cryan, 2014). Our findings that CIE led to increased anxiety-like behavior and selectively increased synaptic excitability in the vHC are consistent with the critical role of this hippocampal subregion in negative affective behaviors (Moser et al., 1995; Moser and Moser, 1998; O’Leary and Cryan, 2014).

Although a detailed characterization of the mechanisms responsible for the differential responsivity of the $\mathrm{vHC}$ and $\mathrm{dHC}$ is beyond the scope of this manuscript, our initial biochemical studies identify two synaptic proteins, GluA2 and SK2, whose expression is selectively altered in the $\mathrm{vHC}$, but not $\mathrm{dHC}$, following CIE exposure. The direction of these changes is consistent with an increase in synaptic excitability and interestingly, these proteins have been shown to be altered following CIE in the hippocampus as well as other brain regions (Christian et al., 2012a; Hopf et al., 2010; Mulholland et al., 2011; Durand and Carlen, 1984). Additionally, similar changes in these proteins have also been observed in models of chronic stress (Caudal et al., 2010, 2016; Gomez-Galan et al., 2016; Rau et al., 2015). One study found that GluA2/3 expression was augmented in the BLA following a $\mathrm{CIE}$ procedure identical to that used in this study, indicating that regions that are monosynaptically connected with the vHC may also exhibit similar neuroadaptations following this ethanol exposure (Christian et al., 2012a). Mulholland and colleagues (2011) found reduced SK2 protein expression in the hippocampus following a modified CIE exposure. Additionally, the calcium-dependent afterhyperpolarization, driven in part by SK channels, was found to be reduced in the hippocampus following three weeks of abstinence from long term ethanol intake (Durand and Carlen, 1984). Neither of these studies differentiated between the $\mathrm{dHC}$ and $\mathrm{vHC}$ but it is possible that the $\mathrm{vHC}$ was driving these alterations as we observed no change in the synaptoneurosomal expression of these proteins in the $\mathrm{dHC}$ after CIE. Interestingly, SK channel expression is higher in the vHC than the $\mathrm{dHC}$ and these channels buffer glutamatergic synaptic activity to a greater extent in the vHC (Babiec et al., 2017). This differential distribution of SK channels may partly explain the differential effects of CIE on synaptic transmission along the dorsal-ventral axis of the hippocampus. 
We also identify two proteins that are not altered following our CIE paradigm, GluN1 and GluN2B, in either hippocampal subunits. These findings are somewhat surprising as other studies have reported increases in the expression of NMDA receptors following CIE (Wills et al., 2017; Nelson et al., 2005; Spencer et al., 2016). Possible reasons for these discordant findings include differences in CIE exposures (number of hours of ethanol vapor/day, number of days of ethanol exposure) and different withdrawal time points. For example, Spencer and colleagues (2016) found increases in GluN1 and GluN2B in the hippocampus following a 4 week CIE exposure (14 hours of ethanol vapor, 10 hours off for 4 days, followed by 3 days off for a total of 4 weeks). Conversely, Wills et al (2017) found no change in both the synaptic and non-synaptic hippocampal GluN2B fractions following CIE exposure (16 hours of ethanol vapor, 8 hours off for 4 days for 2 cycles). Finally, another lab found that one day of withdrawal from ethanol is not enough to induce hippocampal protein expression changes of either GluN1 or GluN2B; however seven days of withdrawal results in an increase in GluN2B receptor expression compared to air controls (Nelson et al., 2005). Interestingly, NMDA receptor activation has been shown to gate SK channel function in the hippocampus (Babiec et al, 2017). Therefore, the absence of any changes in NMDA receptor subunit expression, coupled with the observed alterations in vHC SK2 and GluA2 subunit expression, is actually consistent with the observed increase in synaptic transmission following CIE.

While CIE is a well-validated rodent model of AUD, there are many parallels between the maladaptive behavioral phenotypes promoted by this model and models of stress (Almonte et al., 2017; Holmes et al., 2012; Morales et al., 2015, 2018). For example, the CIE-induced increases in anxiety-like behavior observed in this study parallel the anxiogenic phenotype that emerges following adolescent social isolation, which has been used to model vulnerability to AUD and anxiety disorders (Almonte et al., 2017; Butler et al., 2016; Rau et al., 2015; Skelly et al., 2015). Notably, both models produce increases in anxiety-like behavior, escalations in voluntary ethanol intake, deficits in fear extinction, and increases in depressive-like behaviors (Holmes et al., 2012; Morales et al., 2015, 2018; Rose et al., 2016; Skelly et al., 2015). Consistent with these behavioral changes, both CIE exposure and adolescent social isolation primarily increase synaptic excitation in the ventral domain of the hippocampus (Almonte et al., 2017). In addition, both CIE and adolescent social isolation increase measures of neuronal excitability in the BLA (Diaz et al., 2011; Lack et al., 2007, 2009; Rau et al., 2015). Notably, we have recently demonstrated that the enhanced intrinsic excitability of BLA pyramidal cells following adolescent social isolation is associated with reduced SK subunit expression (Rau et al., 2015). We further show that administration of a positive SK channel modulator can reduce anxiety-like behavior (Rau et al., 2015).

Altogether, these lines of evidence converge upon SK channels as a molecular target that may play an integral role in the neural and behavioral adaptations arising from CIE and adolescent social isolation. Given the strong monosynaptic, reciprocal connections between the BLA and $\mathrm{vHC}$, and the powerful effects of BLA-vHC circuit manipulations on fear- and anxiety-like behaviors (Felix-Ortiz et al., 2013; Felix-Ortiz and Tye, 2014; Huff et al, 2015), it will be of interest in future studies to determine if these circuits are particularly sensitive to CIE and play an integral role in the negative affective state that develops during withdrawal from chronic ethanol. 


\section{Conclusions}

Together, these findings reveal that CIE-associated increases in hippocampal synaptic excitability are restricted to the ventral domain of this brain region. Given the pivotal role of the $\mathrm{vHC}$ in regulating negative affective behaviors, these data may help to explain why increases in anxiety-like behaviors are so prevalent during ethanol withdrawal. The observation that CIE led to a modest decrease in synaptic excitation in the $\mathrm{dHC}$, and that CIE-mediated dysregulation of SN GluA2 and SK2 expression was also restricted to the $\mathrm{vHC}$, add to a growing literature demonstrating that the $\mathrm{dHC}$ and $\mathrm{vHC}$ are distinct structures that exhibit unique responses to a wide range of environmental manipulations. Given that the intrinsic circuitry of the $\mathrm{dHC}$ and $\mathrm{vHC}$ is largely preserved but these structures receive largely non-overlapping inputs from different brain areas, it seems likely that unique CIEassociated adaptations upstream of the hippocampus may have contributed to our findings. Future studies, using opto- and chemogenetic circuit mapping techniques, will be needed to identify the specific afferent inputs to the $\mathrm{vHC}$ that promote CIE-associated increases in synaptic excitability in this brain region.

\section{Acknowledgments}

This work was supported by the NIH/NIAAA awards: AA25819 (SEE); AA26117, AA17531, AA26455, and AA26551 (JLW).

We would also like to thank Kip Zimmerman for his help with the ANCOVA statistical analysis.

\section{References}

Adelman JP, Maylie J, Sah P, 2012 Small-Conductance Ca 2+ -Activated K + Channels: Form and Function. Annu. Rev. Physiol 74, 245-269. 10.1146/annurev-physiol-020911-153336 [PubMed: 21942705]

Almonte AG, Ewin SE, Mauterer MI, Morgan JW, Carter ES, Weiner JL, 2017 Enhanced ventral hippocampal synaptic transmission and impaired synaptic plasticity in a rodent model of alcohol addiction vulnerability. Sci. Rep 7 10.1038/s41598-017-12531-z

Babiec WE, Jami SA, Guglietta R, Chen PB, O’Dell TJ, 2017 Differential Regulation of NMDA Receptor-Mediated Transmission by SK Channels Underlies Dorsal-Ventral Differences in Dynamics of Schaffer Collateral Synaptic Function. J NeurosciJ Neurosci 37, 1950-1964. https:// doi.org/0.1523/JNEUROSCI.3196-16.2017 [PubMed: 28093473]

Bailey KR, Crawley JN, 2009 Anxiety-related behaviors in mice.In: Methods of Behavioral Analysis in Neuroscience, vol. 2 (Buccafusco JJ ed) CRC Press.

Bannerman DM, Grubb M, Deacon RMJ, Yee BK, Feldon J, Rawlins JNP, 2003 Ventral hippocampal lesion affect anxiety but not spatial learning. Behav. Brain Res 139, 197-213, 10.1016/ S0166-4328(02)00268-1. [PubMed: 12642189]

Bannerman DM, Rawlins JNP, McHugh SB, Deacon RMJ, Yee BK, Bast T, Zhang WN, Pothuizen HHJ, Feldon J, 2004 Regional dissociations within the hippocampus - Memory and anxiety. Neurosci. Biobehav. Rev 28, 273-283, 10.1016/j.neubiorev.2004.03.004 [PubMed: 15225971]

Becker HC, 2017 Influence of stress associated with chronic alcohol exposure on drinking. Neuropharmacology122, 115-126, 10.1016/j.neuropharm.2017.04.028 [PubMed: 28431971]

Becker HC, 2008 Alcohol Dependence, Withdrawal, and Relapse.Alcohol Res Health 31, 348-361. [PubMed: 23584009]

Bond CT, Maylie J, Adelman JP, 1999 Small-conductance calcium-activated potassium channels. Ann. N. Y. Acad. Sci 868, 370-378, 10.1111/j.1749-6632.1999.tb11298.x. [PubMed: 10414306] 
Breese GR, Sinha R, Heilig M, 2011 Chronic alcohol neuroadaptation and stress contribute to susceptibility for alcohol craving and relapse. Pharmacol. Ther 129, 149-171. 10.1016/ j.pharmthera.2010.09.007 [PubMed: 20951730]

Butler TR, Karkhanis AN, Jones SR, Weiner JL, 2016 Adolescent Social Isolation as a Model of Heightened Vulnerability to Comorbid Alcoholism and Anxiety Disorders. Alcohol. Clin. Exp. Res 40, 1202-1214. 10.1111/acer.13075 [PubMed: 27154240]

Caudal D, Godsll BP, Mailliet F, Bergerot D, Jay TM 2010 Acute stress induces contrasting changes in AMPA receptor subunit phosphorylation within the prefrontal cortex, amygdala, and hippocampus. PLoS ONE 5, 1-6. 10.1371/journal.pone.0015282.

Caudal D, Rame M, Jay TM, Godsil BP 2016 Dynamic regulation of AMPAR phosphorylation in vivo following acute behavioral stress. Cell Mol Neurobiol 36, 1331-1342. 10.1007/ s10571-016-0332-9 [PubMed: 26814839]

Cagetti E, Pinna G, Guidotti A, Baicy K, Olsen RW, 2004 Chronic intermittent ethanol (CIE) administration in rats decreases levels of neurosteroids in hippocampus, accompanied by altered behavioral responses to neurosteroids and memory function. Neuropharmacology 46, 570-579. 10.1016/j.neuropharm.2003.10.001 [PubMed: 14975681]

Center for Behavioral Health Statistics, S., 2015 Results from the 2014 national survey on drug use and health: detailed tables prevalence estimates, standard errors, $p$ values and sample sizes, SAMHSA.

Christian DT, Alexander NJ, Diaz MR, Robinson S, Mccool BA, 2012a Chronic Intermittent Ethanol and Withdrawal Differentially Modulate Basolateral Amygdala AMPA-type Glutamate Receptor Function and Trafficking. Neuropharmacology 62, 2429-2438. 10.1016/j.neuropharm.2012.02.017

Christian DT, Alexander NJ, Diaz MR, Robinson S, McCool BA, 2012b Chronic intermittent ethanol and withdrawal differentially modulate basolateral amygdala AMPA-type glutamate receptor function and trafficking. Neuropharmacology 62, 2429-2438. 10.1016/j.neuropharm.2012.02.017

Conrad KL, Winder DG, 2011 Altered Anxiety-like Behavior and Long-term Potentiation in the Bed Nucleus of the Stria Terminalis in Adult Mice Exposed to Chronic Social Isolation, Unpredictable Stress and Ethanol Beginning in Adolescence. Alcohol 45, 585-593. 10.1016/j.alcohol. 2010.11.002 [PubMed: 21194878]

Criado JR, Ehlers CL, 2013 Effects of adolescent onset voluntary drinking followed by ethanol vapor exposure on subsequent ethanol consumption during protracted withdrawal in adult Wistar rats. Pharmacol Biochem Behav 103, 622-630. 10.1016/j.pbb.2012.10.016 [PubMed: 23128022]

de Guglielmo G, Crawford E, Kim S, Vendruscolo LF, Hope BT, Brennan M, Cole M, Koob GF, George O, 2016 Recruitment of a Neuronal Ensemble in the Central Nucleus of the Amygdala Is Required for Alcohol Dependence. J. Neurosci 36, 9446-9453. 10.1523/JNEUROSCI. 1395-16.2016 [PubMed: 27605618]

Deacon RMJ, 2013 The successive alleys test of anxiety in mice and rats. JOVE 76, 1-7. https:// doi.org/10.3791/2705.

Den Hartog C, Zamudio-Bulcock P, Nimitvilai S, Gilstrap M, Eaton B, Fedarovich H, Motts A, Woodward JJ, 2016 Inactivation of the lateral orbitofrontal cortex increases drinking in ethanoldependent but not non-dependent mice. Neuropharmacology 107, 451-459. 10.1016/j.neuropharm. 2016.03.031 [PubMed: 27016020]

Diaz MR, Christian DT, Anderson NJ, McCool BA, 2011 Chronic ethanol and withdrawal differentially modulate lateral/basolateral amygdala paracapsular and local GABAergic synapses. J. Pharmacol. Exp. Ther 337, 162-70. 10.1124/jpet.110.177121 [PubMed: 21209156]

Driessen M, 2001 The course of anxiety, depression and drinking behaviours after completed detoxification in alcoholics with and without comorbid anxiety and depressive disorders. Alcohol Alcohol 36, 249-255. 10.1093/alcalc/36.3.249 [PubMed: 11373263]

Durand D, Carlen PL, 1984 Decreased Neuronal Inhibition in vitro after Long-Term Administration of Ethanol. Source Sci. New Ser 224, 1359-1361. 10.1126/science.6328654

Fanselow MS, Dong HW, 2010 Are the Dorsal and Ventral Hippocampus Functionally Distinct Structures? Neuron 65, 7-19. 10.1016/j.neuron.2009.11.031 [PubMed: 20152109] 
Felix-Ortiz A, Beyeler A, Seo C, Leppla C, Wildes CP, Tye K, 2013 BLA to vHPC inputs modulate anxiety-related behaviors. Neuron 79, 658-664. 10.1016/j.neuron.2013.06.016 [PubMed: 23972595]

Felix-Ortiz AC, Tye KM, 2014 Amygdala Inputs to the Ventral Hippocampus Bidirectionally Modulate Social Behavior. J. Neurosci 34, 586-595. 10.1523/JNEUROSCI.4257-13.2014 [PubMed: 24403157]

Finn DA, Snelling C, Fretwell A, Tanchuck MA, Underwood L, Cole M, Crabbe JC, Roberts AJ, 2007 Increased drinking during withdrawal from intermittent ethanol exposure is blocked by the CRF receptor antagonist D-Phe-CRF(12-41). ACER 31, 939-949. 10.1111/j.1530-0277.2007.00379.x.

Gilpin NW, Richardson HN, Cole M, Koob GF, 2008 Vapor inhalation of alcohol in rats. Curr. Protoc. Neurosci Chapter 9, Unit 9.29 10.1002/0471142301.ns0929s44

Gomez-Galan M, Femenia T, Aberg E, Graae L, Van Eeckhaut A, Smolder I, Brene S, Lindskog M, 2016 Running opposes the effects of social isolation on synaptic plasticity and transmission in a rat model of depression. PLos ONE 11, 1-11. 10.1371/journal.pone.0165071.

Guilbert JJ, 2003 The world health report 2002 - Reducing risks, promoting healthy life. Educ. Heal $10.1080 / 1357628031000116808$

Hendricson AW, Maldve RE, Salinas AG, Theile JW, Zhang TA, Diaz LM, Morrisett RA, 2007 Aberrant synaptic activation of N-Methly-D-aspartate receptors underlies ethanol withdrawal hyperexcitability. Journal of Pharmacology and Experimental Therapeutics 321, 60-72. 10.1124/ jpet.106.111419. [PubMed: 17229881]

Henke PG, 1990 Hippocampal pathway to the amygdala and stress ulcer development. Brain Res. Bull 25, 691-695. 10.1016/0361-9230(90)90044-Z [PubMed: 2289157]

Holmes A, Fitzgerald PJ, MacPherson KP, DeBrouse L, Colacicco G, Flynn SM, Masneuf S, Pleil KE, Li C, Marcinkiewcz CA, Kash TL, Gunduz-Cinar O, Camp M, 2012 Chronic alcohol remodels prefrontal neurons and disrupts NMDAR-mediated fear extinction encoding. Nat. Neurosci 15, 1359-1361. 10.1038/nn.3204 [PubMed: 22941108]

Hopf FW, Bowers MS, Chang S-J, Chen BT, Martin M, Seif T, Cho SL, Tye K, Bonci A, 2010a Reduced nucleus accumbens SK channel activity enhances alcohol seeking during abstinence. Neuron 65, 682-94. 10.1016/j.neuron.2010.02.015 [PubMed: 20223203]

Hopf FW, Seif T, Mohamedi ML, Chen BT, Bonci A, 2010b The small-conductance calcium-activated potassium channel is a key modulator of firing and long-term depression in the dorsal striatum. Eur. J. Neurosci 31, 1946-59. 10.1111/j.1460-9568.2010.07231.x [PubMed: 20497469]

Huff ML, Emmons EB, Narayanan NS, Lalumiere RT, 2015 Basolateral amygdala projections to ventral hippocampus modulate the consolidation of footshock, but not contextual, learning in rats. Learn. Mem 23, 51-60. 10.1101/lm.039909.115

Jung MW, Wiener SI, McNaughton BL, 1994 Comparison of spatial firing characteristics of units in dorsal and ventral hippocampus of the rat. J. Neurosci 14, 7347-7356. 10.1523/jneurosci. 4759-06.2007 [PubMed: 7996180]

Kjelstrup KG, Tuvnes FA, Steffenach H-A, Murison R, Moser EI, Moser M-B, 2002a Reduced fear expression after lesions of the ventral hippocampus. Proc. Natl. Acad. Sci 99, 10825-10830. 10.1073/pnas.152112399 [PubMed: 12149439]

Koob GF, 2015 Alcohol use disorders: tracts, twins, and trajectories. Am. J. Psychiatry 172, 499-501. 10.1176/appi.ajp.2015.15020240 [PubMed: 25982661]

Koob GF, Volkow ND, 2016 Neurobiology of addiction: a neurocircuitry analysis. www.thelancet.com Rev. Lancet Psychiatry 3, 760-73. 10.1016/S2215-0366(16)00104-8 [PubMed: 27475769]

Kushner MG, Abrams K, Thuras P, Hanson KL, Brekke M, Sletten S, 2005 Follow-up study of anxiety disorder and alcohol dependence in comorbid alcoholism treatment patients. Alcohol. Clin. Exp. Res 29, 1432-1443. 10.1097/01.alc.0000175072.17623.f8 [PubMed: 16131851]

Kushner MG, Maurer E, Menary K, Thuras P, 2011 Vulnerability to the Rapid ("Telescoped”) Development of Alcohol Dependence in Individuals with Anxiety Disorder. J. Stud. Alcohol Drugs 72, 1019-1027. 10.15288/jsad.2011.72.1019. [PubMed: 22051216]

Läck AK, Ariwodola OJ, Chappell AM, Weiner JL, McCool BA, 2008 Ethanol inhibition of kainate receptor-mediated excitatory neurotransmission in the rat basolateral nucleus of the amygdala. Neuropharmacology 55, 661-668. 10.1016/j.neuropharm.2008.05.026 [PubMed: 18617194] 
Läck AK, Christian DT, Diaz MR, Mccool BA, Mccool B, 2009 Chronic ethanol and withdrawal effects on kainate receptor-mediated excitatory neurotransmission in the rat basolateral amygdala. Alcohol 43, 25-33. 10.1016/j.alcohol.2008.11.002 [PubMed: 19185207]

Läck AK, Diaz MR, Chappell A, DuBois DW, McCool BA, 2007 Chronic ethanol and withdrawal differentially modulate pre- and postsynaptic function at glutamatergic synapses in rat basolateral amygdala. J. Neurophysiol 98, 3185-96. 10.1152/jn.00189.2007 [PubMed: 17898152]

Lahmann C, Clark RH, Iberl M, Ashcroft FM, 2017 A mutation causing increased KATP channel activity leads to reduced anxiety in mice. Physiol Behav 44, 79-84. 10.1016/j.physbeh. 2014.02.031.

Maggio N, Segal M, 2009 Differential modulation of long-term depression by acute stress in the rat dorsal and ventral hippocampus. J. Neurosci 29, 8633-8638. 10.1523/JNEUROSCI.1901-09.2009. [PubMed: 19587269]

Maggio N, Segal M, 2007 Unique regulation of long term potentiation in the rat ventral hippocampus. Hippocampus 17, 10-25. 10.1002/hipo.20237. [PubMed: 17094146]

Marcinkiewcz CA, Mazzone CM, D’Agostino G, Halladay LR, Hardaway JA, DiBerto JF, Navarro M, Burnham N, Cristiano C, Dorrier CE, Tipton GJ, Ramakrishnan C, Kozicz T, Deisseroth K, Thiele TE, McElligott ZA, Holmes A, Heisler LK, Kash TL, 2016 Serotonin engages an anxiety and fearpromoting circuit in the extended amygdala. Nature 537, 97-101. 10.1038/nature19318. [PubMed: 27556938]

Maruki K, Izaki Y, Nomura M, Yamauchi T, 2001 Differences in paired-pulse facilitation and longterm potentiation between dorsal and ventral CA1 regions in anesthetized rats. Hippocampus 11, 655-661. 10.1002/hipo.1080 [PubMed: 11811659]

Morales M, Mcginnis MM, Mccool BA, 2015 Chronic ethanol exposure increases voluntary home cage intake in adult male, but not female, Long-Evans rats. Pharmacol. Biochem. Behav 139, 6776. 10.1016/j.pbb.2015.10.016 [PubMed: 26515190]

Morales M, McGinnis MM, Robinson SL, Chappell AM, McCool BA, 2018 Chronic Intermittent Ethanol Exposure Modulation of Glutamatergic Neurotransmission in Rat Lateral/Basolateral Amygdala is Duration-, Input-, and Sex-Dependent. Neuroscience 371, 277-287. 10.1016/ J.NEUROSCIENCE.2017.12.005 [PubMed: 29237566]

Moser MB, Moser EI, 1998 Functional differentiation in the hippocampus. Hippocampus 8, 608-619. 10.1002/(SICI)1098-1063(1998)8:6\&lt;608::AID-HIPO3\&gt;3.0.CO;2-7 [PubMed: 9882018]

Moser MB, Moser EI, Forrest E, Andersen P, Morris RG, 1995 Spatial learning with a minislab in the dorsal hippocampus. Proc. Natl. Acad. Sci 92, 9697-9701. 10.1073/pnas.92.21.9697 [PubMed: 7568200]

Mulholland PJ, Becker HC, Woodward JJ, Chandler LJ, 2011 Small conductance calcium-activated potassium type 2 channels regulate alcohol-associated plasticity of glutamatergic synapses. Biol. Psychiatry 69, 625-632. 10.1016/j.biopsych.2010.09.025 [PubMed: 21056409]

Mulholland PJ, Hopf FW, Bukiya AN, Martin GE, Liu J, Dopico AM, Bonci A, Treistman SN, Chandler LJ, 2009 Sizing up Ethanol-Induced Plasticity: The Role of Small and Large Conductance Calcium-Activated Potassium Channels. Alcohol 33, 1125-1135. 10.1111/j. 1530-0277.2009.00936.x.Sizing

Nelson TE, Ur CL, Gruol DL, 2005 Chronic intermittent ethanol exposure enhances NMDA-receptormediated synaptic responses and NMDA receptor expression in hippocampal CA1 region. Brain Res 1048, 69-79. 10.1016/j.brainres.2005.04.041 [PubMed: 15919065]

Nelson TE, Ur CL, Gruol DL, 1999 Chronic intermittent ethanol exposure alters CA1 synaptic transmission in rat hippocampal slices. Neurosci 94, 431-442. 10.1016/S0306-4522(99)00336-X

Niere F, Namjoshi S, Song E, Dilly GA, Schoenhard G, Zemelman BV, Mechref Y, Raab-Graham KF, 2016 Analysis of Proteins That Rapidly Change Upon Mechanistic/Mammalian Target of Rapamycin Complex 1 (mTORC1) Repression Identifies Parkinson Protein 7 (PARK7) as a Novel Protein Aberrantly Expressed in Tuberous Sclerosis Complex (TSC). Mol. Cell. Proteomics 15, 426-444. 10.1074/mcp.M115.055079 [PubMed: 26419955]

O’Dell LE, Roberts AJ, Smith RT, Koob GF, 2004 Enhanced Alcohol Self-Administration after Intermittent Versus Continuous Alcohol Vapor Exposure. Alcohol. Clin. Exp. Res 28, 1676-1682. 10.1097/01.ALC.0000145781.11923.4E [PubMed: 15547454] 
O'Leary OF, Cryan JF, 2014 A ventral view on antidepressant action: Roles for adult hippocampal neurogenesis along the dorsoventral axis. Trends Pharmacol. Sci 35, 675-687. 10.1016/j.tips. 2014.09.011 [PubMed: 25455365]

Paxinos G, Watson C, 2004 In: The rat brain in stereotaxic coordinates, vol. 5, Elsevier Academic Press.

Pleil KE, Lowery-Gionta EG, Crowley NA, Li C, Marcinkiewcz CA, Rose JH, Mccall NM, Maldonado-Devincci AM, Morrow AL, Jones SR, Kash TL, 2015 Effects of chronic ethanol exposure on neuronal function in the prefrontal cortex and extended amygdala HHS Public Access. Neuropharmacology 99, 735-749. 10.1016/j.neuropharm.2015.06.017 [PubMed: 26188147]

Potvin O, Doré FY, Goulet S, 2007 Contributions of the dorsal hippocampus and the dorsal subiculum to processing of idiothetic information and spatial memory. Neurobiol. Learn. Mem 87, 669-678. 10.1016/j.nlm.2007.01.002 [PubMed: 17317229]

Quinlan EM, Philpot BD, Huganir RL, Bear MF, 1999 Rapid, expression of synaptic NMDA receptors in visual cortex in vivo. Nat Neurosci 2, 352-357. https://doi:10.1038/7263. [PubMed: 10204542]

Ramos A, Mormede P, 1998 Stress and emotionality: a multidimensional and genetic approach. Neuroscience and Biobehavioral Reviews 22, 33-57. https://doi:10.1016/S0149-7634(97)00001-8. [PubMed: 9491939]

Rau AR, Chappell AM, Butler TR, Ariwodola OJ, Weiner JL, 2015 Increased Basolateral Amygdala Pyramidal Cell Excitability May Contribute to the Anxiogenic Phenotype Induced by Chronic Early-Life Stress. J. Neurosci 35, 9730-40. 10.1523/JNEUROSCI.0384-152015 [PubMed: 26134655]

Reynolds SM, Berridge KC, 2008 Emotional environments retune the valence of appetitive versus fearful functions in nucleus accumbens. Nat Neurosci 11, 423-425. 10.1038/nn2061 [PubMed: 18344996]

Risold PY, Swanson LW, 1996 Structural evidence for functional domains in the rat hippocampus. Science 272 1484-1486. 10.1126/science.272.5267.1484 [PubMed: 8633241]

Roberto M, Nelson TE, Ur CL, Gruol DL, 2002 Long-Term Potentiation in the Rat Hippocampus Is Reversibly Depressed by Chronic Intermittent Ethanol Exposure. J Neurophysiol 87, 2385-2397. 10.1152/jn.00145.2001 [PubMed: 11976376]

Rodgers RJ, Cao BJ, Dalvi A, Holmes A, 1997 Animal models of anxieyt: an ethological perspective. Braz J Med Biol Res 30, 289-304. 10.1590/S0100-879X1997000300002. [PubMed: 9246227]

Rose J, Karkhanis A, Steiniger-Brach B, Jones S, 2016 Distinct Effects of Nalmefene on Dopamine Uptake Rates and Kappa Opioid Receptor Activity in the Nucleus Accumbens Following Chronic Intermittent Ethanol Exposure. Int. J. Mol. Sci 17, 1216 10.3390/ijms17081216

Rose JH, Karkhanis AN, Chen R, Gioia D, Lopez MF, Becker HC, McCool BA, Jones SR, 2016 Supersensitive kappa opioid receptors promotes ethanol withdrawal-related behaviors and reduce dopamine signaling in the nucleus accumbens. Int. J. Neuropsychopharmacol 19, 1-10. 10.1093/ ijnp/pyv127

Rudebeck PH, Walton ME, Millette BHP, Shirley E, Rushworth MFS, Bannerman DM, 2007 Distinct contributions of frontal areas to emotion and social behavior in the rat. European Journal of neuroscience 26, 2315-2326. 10.1111/j.1460-9568.2007.05844.x [PubMed: 17927774]

Schellekens AFA, de Jong CAJ, Buitelaar JK, Verkes RJ, 2015 Co-morbid anxiety disorders predict early relapse after inpatient alcohol treatment. Eur. Psychiatry 30, 128-136. 10.1016/j.eurpsy. 2013.08.006 [PubMed: 24630346]

Sidhu H, Kreifeldt M, Content C, 2018 Affective disturbances during withdrawal from chronic intermittent ethanol inhalation in C57BL/6J and DBA/2J male mice. Alcohol. Clin. Exp. Res 10.1111/acer.13760

Sinha R, Fox HC, Adam Hong K, Hansen J, Tuit K, Jeanne Kreek M, 2011 Effects of Adrenal Sensitivity, Stress-and Cue-Induced Craving, and Anxiety on Subsequent Alcohol Relapse and Treatment Outcomes. Arch. Gen. Psychiatry 9, 942-952. 10.1001/archgenpsychiatry.2011.49

Sinha R, Fox HC, Hong KA, Bergquist K, Bhagwagar Z, Siedlarz KM, 2009 Enhanced negative emotion and alcohol craving, and altered physiological responses following stress and cue 
exposure in alcohol dependent individuals. Neuropsychopharmacology 34, 1198-208. 10.1038/ npp.2008.78 [PubMed: 18563062]

Skelly MJ, Chappell AE, Carter E, Weiner JL, 2015 Adolescent social isolation increases anxiety-like behavior and ethanol intake and impairs fear extinction in adulthood: Possible role of disrupted noradrenergic signaling. Neuropharmacology 97, 149-159. 10.1016/j.neuropharm.2015.05.025 [PubMed: 26044636]

Smith JP, Randall CL, 2012 Anxiety and alcohol use disorders: comorbidity and treatment considerations. Alcohol Res 34, 414-31. [PubMed: 23584108]

Spencer KB, Mulholland PJ, Chandler LJ, 2016 FMRP mediates chronic ethanol induced changes in NMDA, Kv4.2, and KChIP3 expression in the hippocampus. Alcohol Clin Exp Res 40, 12511261. 10.1111/acer.13060. [PubMed: 27147118]

Strange BA, Witter MP, Lein ES, Moser EI, 2014 Functional organization of the hippocampal longitudinal axis. Nat. Rev. Neurosci 15, 655-669. 10.1038/nrn3785 [PubMed: 25234264]

Tannenholz L, Jimenez JC, Kheirbek MA, 2014 Local and regional heterogeneity underlying hippocampal modulation of cognition and mood. Front. Behav. Neurosci 8, 147 10.3389/fnbeh. 2014.00147 [PubMed: 24834033]

Valdez GR, Roberts AJ, Chan K, Davis H, Brennan M, Zorrilla EP, Koob GF, 2002 Increased ethanol self-administration and anxiety-like behavior during acute ethanol withdrawal and protracted abstinence: regulation by corticotropin-releasing factor. Alcohol Clin Exp Res 26, 1494-1501. 10.1097/01.ALC.0000033120.51856.F0 [PubMed: 12394282]

Vendruscolo LF, Roberts AJ, 2014 Operant alcohol self-administration in dependent rats: Focus on the vapor model. Alcohol 3, 277-286. 10.1016/j.alcohol.2013.08.006

Wills T, Baucum AJ, Louderback KM, Chen Y, Pasek JG, Delpire E, Tabb DL, Colbran RJ, Winder DG 2017 Chronic intermittent alcohol disrupts the GluN2B-associated proteome and specifically regulates group I mGlu receptor dependent long-term depression. Addict Biol 22, 275-290. 10.1111/j.2040-1124.2010.00046.x [PubMed: 26549202]

Wills TA, Klug JR, Silberman Y, Baucum AJ, Weitlauf C, Colbran RJ, Delpire E, Winder DG 2012 GluN2B subunit deletion reveals key role in acute and chronic ethanol sensitivity of glutamate synapses in bed nucleus of stria terminalis. Proc Natl Acad Sci 109, 278-287. 10.1073/pnas. 1113820109.

Whittington MA, Little HJ, 1990 Patterns of changes in field potentials in the isolated hippocampal slice on withdrawal from chronic ethanol treatment of mice in vivo. Brain Res 523, 237-244. 10.1016/0006-8993(90)91492-Y [PubMed: 2400909]

Workman ER, Niere F, Raab-Graham KF, 2013 mTORC1-dependent protein synthesis underlying rapid antidepressant effect requires GABABR signaling. Neuropharmacology 73, 192-203. 10.1016/j.neuropharm.2013.05.037 [PubMed: 23752093]

Zhao Y, Weiss F, Zorrilla EP, 2007 Remission and resurgence of anxiety-like behavior across protracted withdrawal stages in ethanol-dependent rats. Alcohol Clin Exp Res 31, 1505-1515. 10.1111/j.1530-0277.2007.00456.x [PubMed: 17760785] 


\section{Highlights}

- Chronic intermittent ethanol exposure increases multiple measures of in anxiety-like behavior in male Long Evans rats.

- Chronic intermittent ethanol exposure increases synaptic excitability in the ventral, but not the dorsal, domain of the hippocampus.

- These changes are associated with ventral hippocampal alterations in synaptosomal expression of SK2 and GluA2 subunits. 

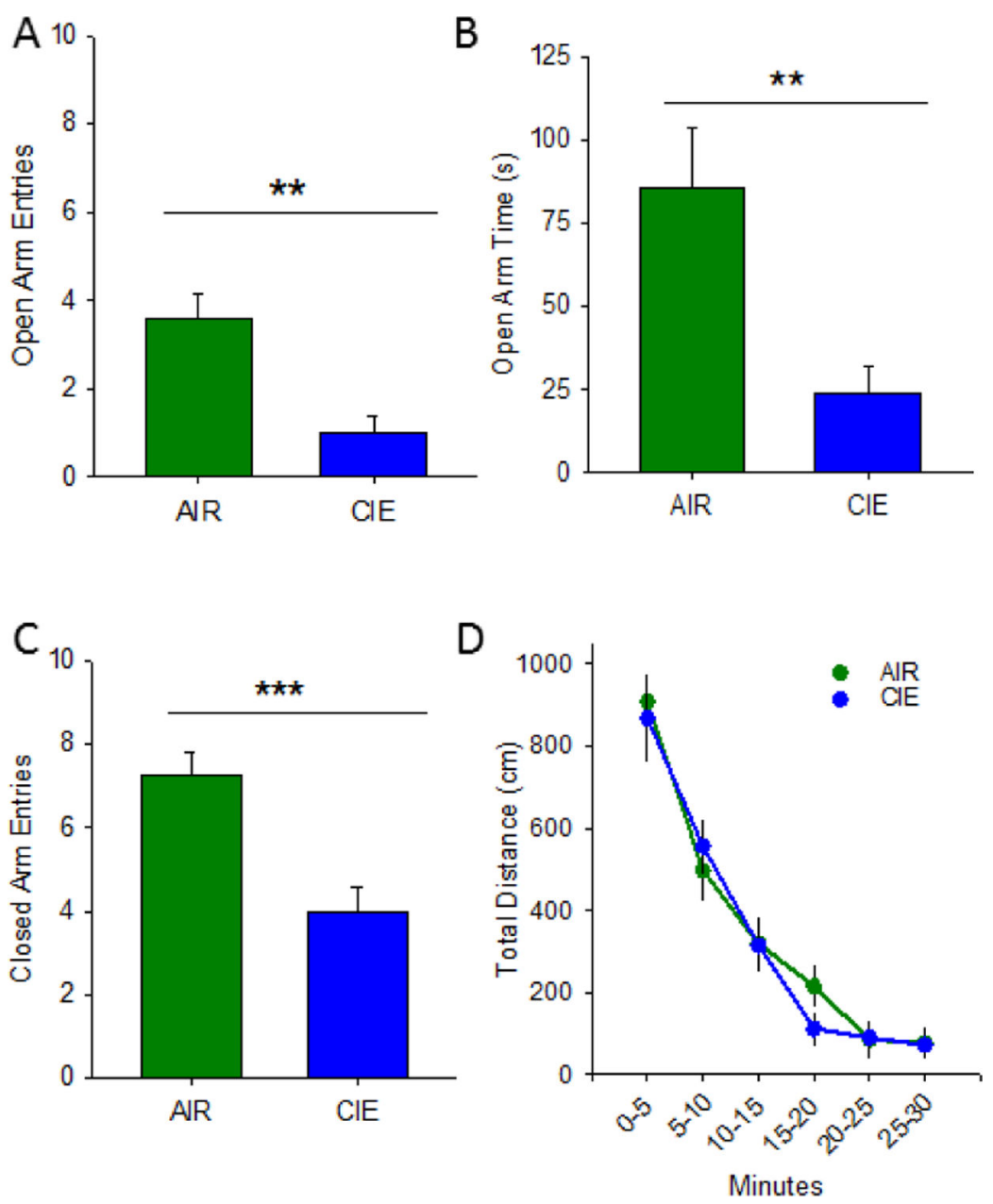

Figure 1.

Chronic intermittent ethanol increases anxiety-like behavior in the elevated plus-maze. AIR exposed $(\mathrm{N}=12)$ rats exhibited less anxiety-like behavior on the elevated plus-maze than CIE ( $N=12)$ counterparts, as evidenced by more time spent in the open arms (A) and more open arm entries (B). AIR rats also exhibited a greater number of closed arm entries (C). Additionally, AIR and CIE rats do not exhibit differences in locomotor activity in the open field test $(\mathrm{D} ; * *, \mathrm{p}<0.01, * * * . \mathrm{p}<0.001)$. 

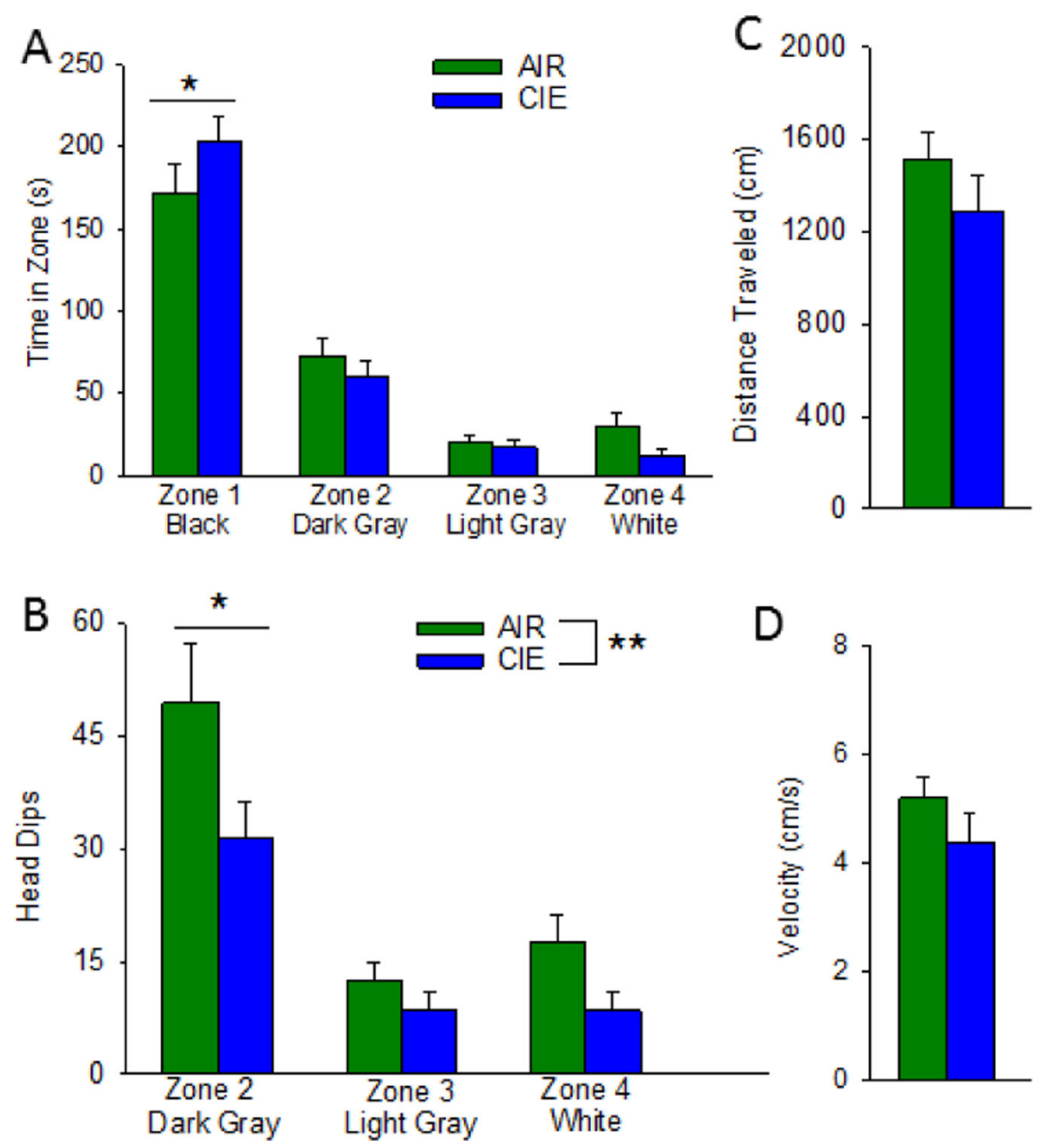

Figure 2.

Chronic intermittent ethanol increases anxiety-like behavior in the successive alleys test. AIR exposed $(\mathrm{N}=19)$ rats exhibited less anxiety-like behavior indicated by spending less time in zone 1 (A) relative to their CIE ( $N=18)$ counterparts. CIE rats spent significantly less time head dipping in zone 2 (B) relative to AIR rats. Additionally, AIR and CIE rats did not differ in the distance traveled (C) or velocity $(\mathrm{D} ; *, \mathrm{p}<0.05$, **, $\mathrm{p}<0.01)$. 

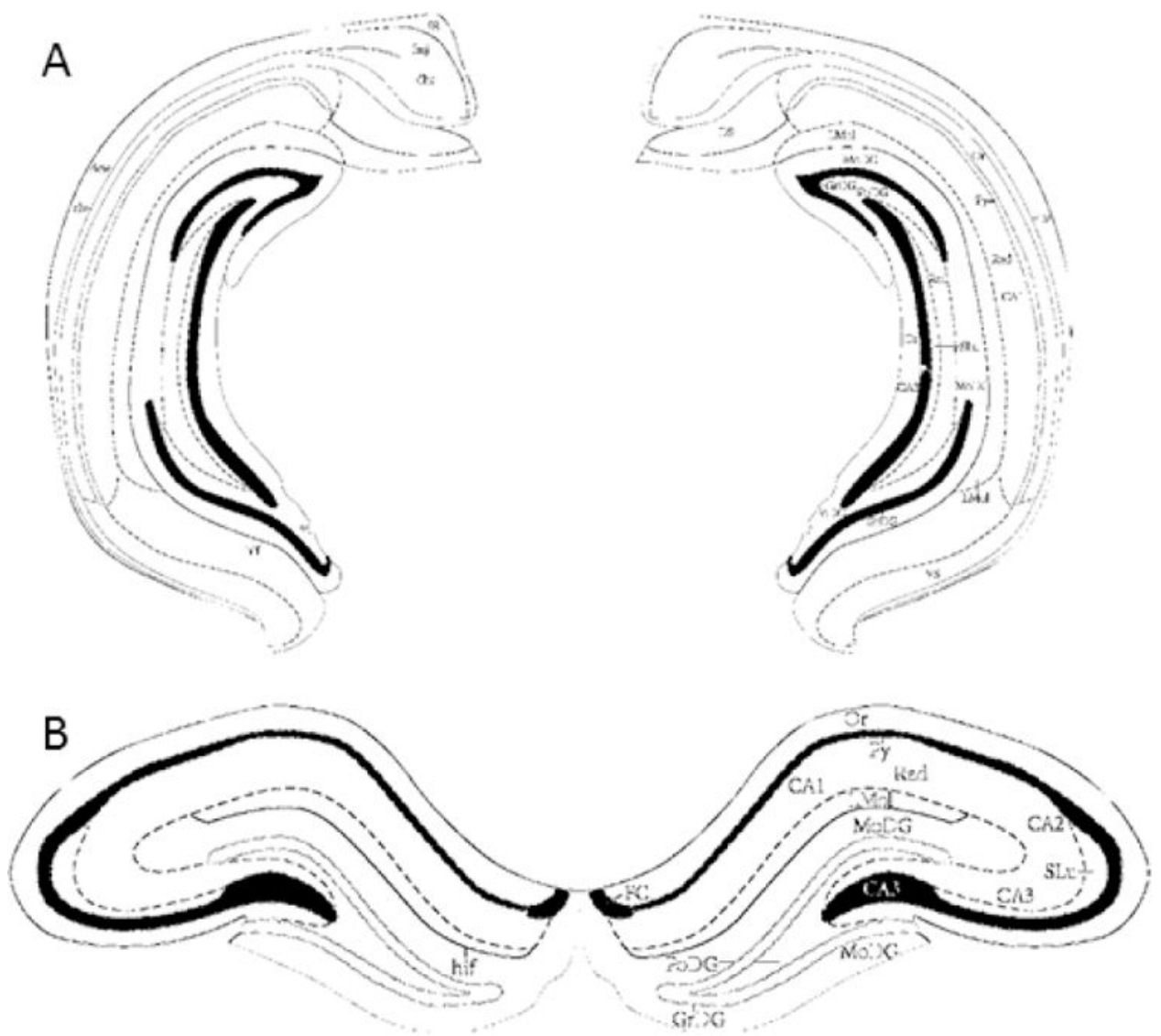

Figure 3.

Illustrations of morphological differences in coronal slices from ventral and dorsal hippocampus. Representative images adapted from Paxinos and Watson (2005) depicting the ventral (A; Bregma $-5.52 \mathrm{~mm}$ ) and dorsal hippocampus (B; Bregma $-3.12 \mathrm{~mm}$ ) for extracellular field recordings. 

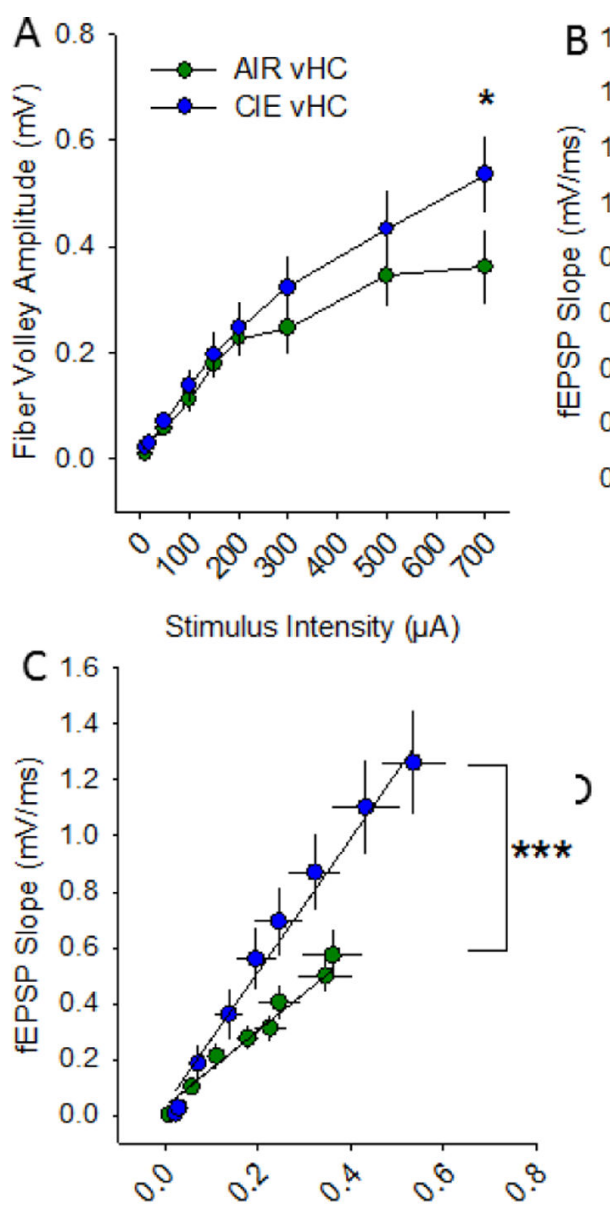

Fiber Volley Amp litude (mV)

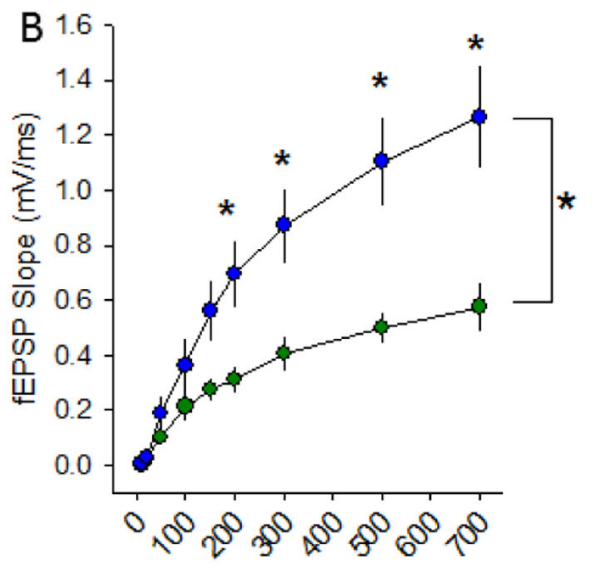

Stimulus Intensity $(\mu \mathrm{A})$
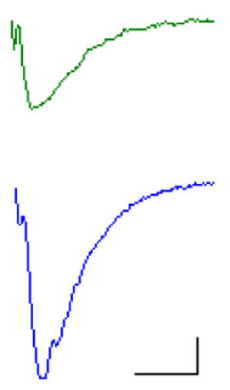

Figure 4.

Withdrawal from chronic intermittent ethanol increases synaptic excitability at vHC Schaffer collateral-CA1 synapses. Plots of stimulation intensity vs fiber volley amplitude (A) and fEPSP slope (B) in vHC slices from AIR and CIE rats. C) Plot of the relationship between fiber volley amplitude and fEPSP slope in vHC slices from AIR and CIE rats.

Representative fEPSPs evoked at $200 \mu \mathrm{A}$ from AIR and CIE slices. *, p<0.05, ***, p<0.001, $\mathrm{AIR}=6$ slices, 5 rats; CIE $\mathrm{n}=8$ slices, 7 rats). 

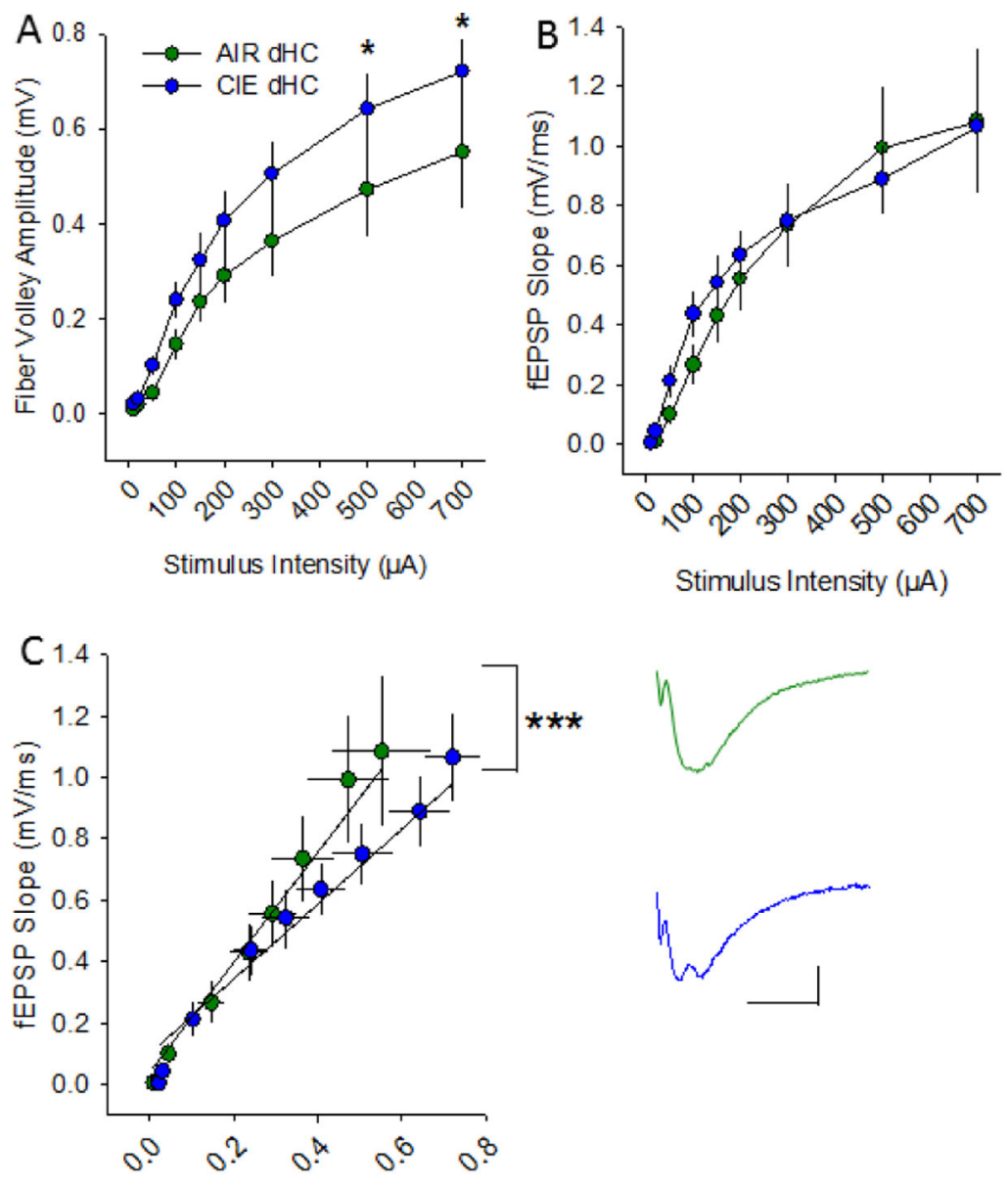

Fiber Volley Amplitude (mV)

Figure 5.

Withdrawal from chronic intermittent ethanol decreases synaptic excitability at dHC Schaffer collateral-CA1 synapses. Plots of stimulation intensity vs fiber volley amplitude (A) and fEPSP slope (B) in $\mathrm{dHC}$ slices from AIR and CIE rats. C) Plot of the relationship between fiber volley amplitude and fEPSP in dHC slices from AIR and CIE rats.

Representative fEPSPs evoked at $200 \mu \mathrm{A}$ from AIR and CIE slices ${ }^{*}, \mathrm{p}<0.05$, AIR $\mathrm{n}=10$ slices, 9 rats; CIE n $=9$ slices, 8 rats). 

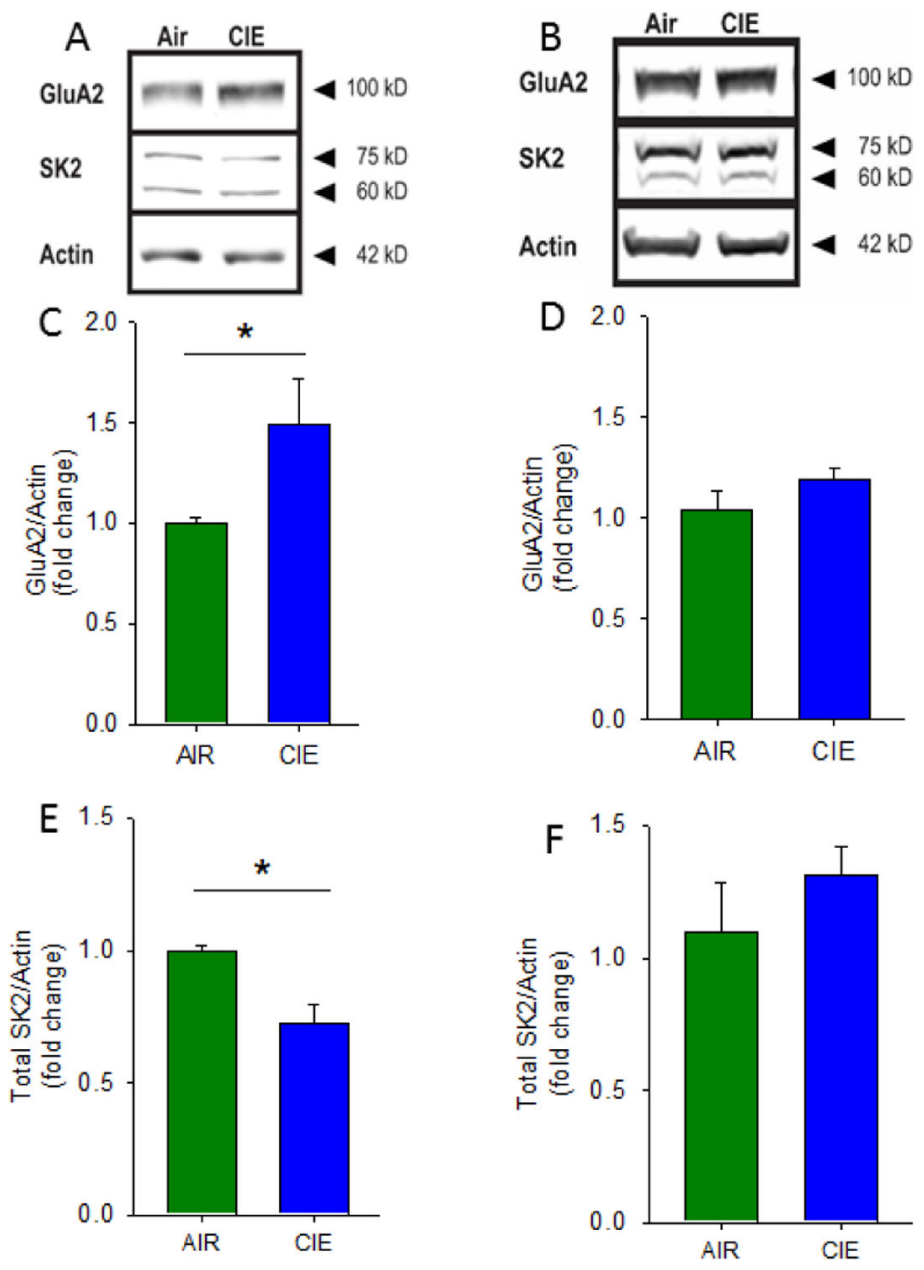

Figure 6.

Chronic intermittent ethanol has divergent effects on GluA2 and SK2 protein expression in the ventral and dorsal hippocampus. Representative Western blots of synaptoneurosomes isolated from AIR and CIE vHC (A) and dHC (B) tissue. Group data, normalized to actin, illustrating increased GluA2 protein expression in CIE vHC (C) and not in $\mathrm{dHC}$ (D). Group data, normalized to actin, illustrating decreased SK2 protein expression in CIE vHC (E) and not in $\mathrm{dHC}(\mathrm{F} ; *, \mathrm{p}<0.05, \mathrm{AIR}=3$ rats, $\mathrm{CIE}=3$ rats $)$. 

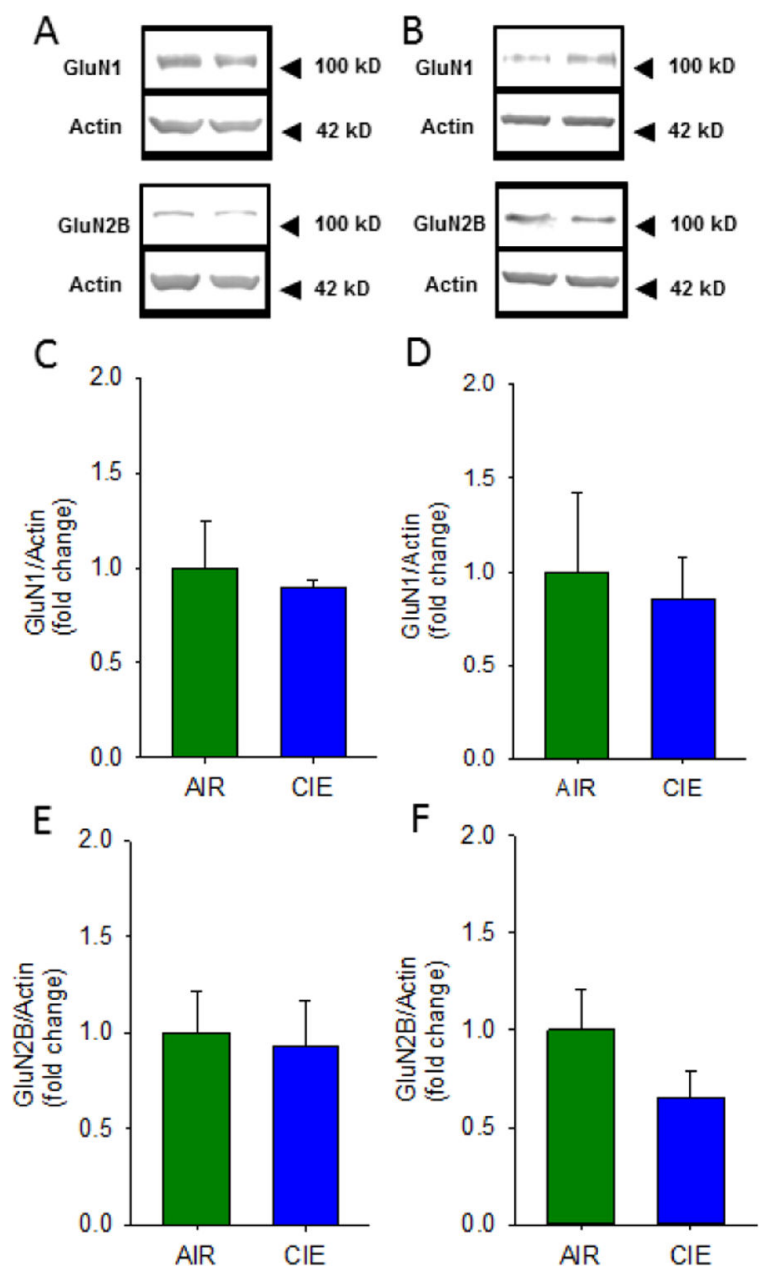

Figure 7.

Chronic intermittent ethanol exposure does not alter GluN1 and GluN2B protein expression in the ventral or dorsal hippocampus. Representative Western blots of synaptoneurosomes isolated from AIR and CIE vHC (A) and dHC (B) tissue. Group data, normalized to actin, illustrating no changes in GluN1 protein expression in vHC (C) or dHC (D) of AIR and CIE exposed rats. Group data, normalized to actin, illustrating no changes in GluN2B protein expression in vHC (E) or $\mathrm{dHC}(\mathrm{F})$ of AIR and CIE exposed rats (AIR $=4$ rats, $\mathrm{CIE}=4$ rats). 